\title{
Inhalts-Verzeichniss.
}

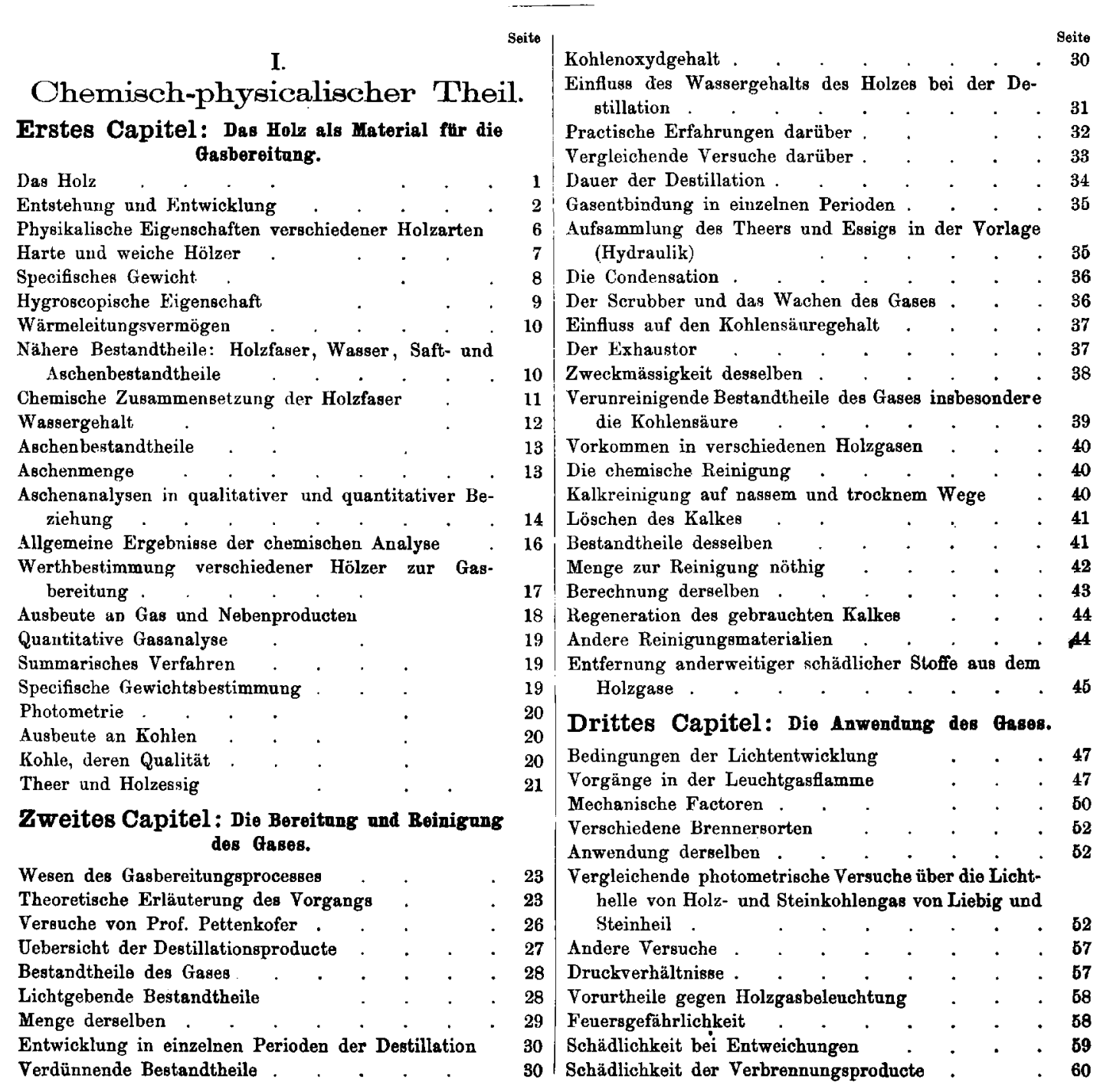


VIII

Versuche und Tabellen . . . . . . $\quad \begin{array}{r}\text { Seito } \\ 61\end{array}$ Vorzug des Holzgases wegen fehlenden Schwefelgehalts Wohlfeilheit

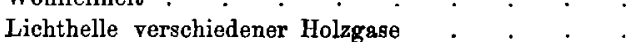

Kochen mit Gas.

Viertes Capitel : Die Nebenproducte der Holsgasfabrication.

Der Holztheer

.

• . • • 64

Anwendung zur Gasbereitung, zur Feuerung, zur Dach-

pappe und zum Anstrich

Theerdestillation

Leichtes und schweres Theeröl

Anwendung dieser Oele

Paraffin

Der Holzessig

Eigenschaften

Zahlreiche Bestandtheile

Gehaltsbestimmung an reiner Essigsäure

Verschiedene Methoden dazu

Ausbeute an Essig

Essigkalk

Zweckmässigste Bereitung desselben.

Die Oxyphensäure

Das Ammoniak

Der Holzgeist

Die Holzkohlen

Eigenschaften; spec. Gewicht . .

Absorptionsvermögen für Feuchtigkeit und Luft

Chemische Zusammensetzung

Ausbeute

Sortirung der Kohlen.

Anwendung derselben

II.

\section{Technischer Theil.}

Fünftes Capitel: Die Retortenofon mit der Vorlage.

Die ersten Retorten und s. g. Generatoren

Vereinfachung dieser Apparate

Eisen- und Thonretorten

Versuche von Herrn Geith

Mundstück der Retorte

Retortenverschluss

Ofen mit 3 Eisenretorten

Kostenberechnung desselben

Andrer Ofen mit 3 Eisenretorten

Ofen mit 2 und 1 Eisenretorten

Oefen mit Thonretorten

Der Feverraum und seine Verhältinisse

Rost, Roststäbe und Aschenheerd

Der Weg des Feuers durch den Ofen

Rauchcanal

Arbeitsgeräthe
4 Z

D

64 Ge

.

Eilftes Capitel: Die Condensatoren and Waschapparate.

Zweck derselben . . . . . 114

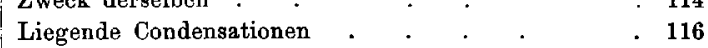

Vortheile und Nachtheile dieser; Kühlfiäche . 116

Der Wascher oder Scrubber . . 116

Füllung . . . . . 117

\section{Zwölftes Capitel: Der Exhaustor.}

Zweck desselben . . . . . . . 117

$\begin{array}{ll}\text { Beschreibung eines Grafton'schen Exhaustors } & 117\end{array}$

Exhaustor von Beale . . 118

Dreizehntes Capitel: Die Reinigungsapparate and das Reinigungshaus.

Nasse Reinigung mit Kalk . . . . 119

Apparat hierzu . . . . . . . . 120

Trockene Reinigung . . . . . . . . 121

Reiniger von Gusseisen, Holz und Mauerwerk . . 121

Grösse derselben. . . . . . . . 122

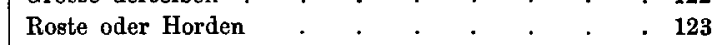

Vorrichtungen zum Heben der Deckel . . . 123 
Der Betrieb mit drei Reinigern in kleinen Angtalten Vorschriften für das Reinigungshaus. . . . 124 Vorbau

Vierzehntes Capitel: Die Fabrications-Gasnhr.

Einrichtung

Einfluss der Temperatur auf die Messung.

Berechnung des wirklichen Durchgange von Gas

Fünfzehntes Capitel: Dio Gasbehilter.

Construction und Ausführung derselben

Berechnung des Druckes für Holzgas

Sechszehntes Capitel: Regalator and Drackmesser.

Siebenzehntes Capitel: Die Leitungsröhren.

Bedingungen für eine gute Leitung

Formel von W. Pole mit Correction

Dimensionen der Röhren für Hausleitungen

Dimensionen der Röhren für Strassenleitungen.

Tabelle über Ausströmungsmenge

Dimensioneu der Zuleitungsrohre

Disposition für Herstellung ganzer Röhrennetze

Berücksichtigung der Höhenlage

Material für die Rohre

Dichtungen

Dichtung mit Gummiringen

Prüfung der hergestellten Rohrleitungen

Ueber Leckage

\section{Achtzehntes Capitel: Das Essighans.}

Zweck und Ausführung desselben Beschreibung eines Essighauses mit drei Abdampfpfannen

Die Abdampefannen

Die Bütten zum Aufsammeln

Ventilation des Essighauses
Neunzehntes Capitel: Die Gasuhren. $\quad 137$

III.

Anhang.

Gas aus Sagemehl . . . . . 138

Gas ans Spänen and Bindentheilen . . 139

Gas ans Tannenkpfeln . . . . 140

Gas aus den Samenflitgeln verschiedener Tannen-

aud Fichtensamen . . . . . . . 141

Gas ans den Rtickstainden der Haceration trockner Rtiben . . . . . . . . . 142 Gas aus Torf.

Entstehung des Torfs . . . . 143

Eintheilung der Torfarten . . . . . 145

Physikalische Eigenschaften derselben 147

Chemische Zusammensetzung . . . . 147

Aschenanalysen in quantitativer Beziehung $\quad \therefore 148$

Aschenanalysen irischer Torfarten . . . 150

Werthbestimmung zur Gasbereitung . . . . 154

Producte die bei der Gasbereitung auftreten . , 155

Schilderung der Gasbereitung aus Haspelmoorer Torf 157

Ausbeute an Gas; Ladezeit . . . . . 157

Gasentwicklung in verschiedenen Perioden . . 158

Kohlensäuregehalt . . . . . . . 150

Torfkohle; Theer, Ammoniakwasser $\quad . \quad \cdot \quad . \quad+159$

Bchilderang der Gasbereitang ans gew. braunem Torfe 160

Ausbeute . . . . . . . . 160

134 Gasentwicklung in verschiedenen Perioden $\quad \cdot 161$

Kohlengäuregehalt , . . . . . . 161

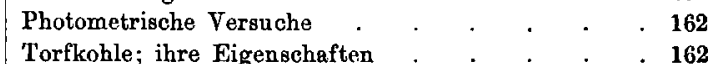

Schilderong der Gasbereitung aus Rasentorf von

Sohilling . . . . . . . . . 163

Versuche Torfgas au bereiten von Hrn. Körner und Specker . . . . . . . . 164

Versuche Torfgas su bereiten von Hrn. Schuppler 165

Verzeichniss der Figurentafeln.

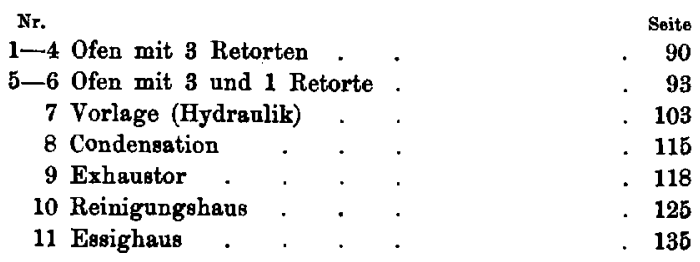

